\title{
PARTICIPATORY APPROACH IN THE DESIGN OF CREATIVE COMMUNITY SPACES IN SURABAYA
}

\author{
Diana Thamrin ${ }^{1 *}$, Laksmi K. Wardani ${ }^{1}$, Ronald H.I. Sitindjak ${ }^{1}$, Listia Natadjaja ${ }^{1}$ \\ ${ }^{1}$ Faculty of Art and Design, Petra Christian University, Indonesia
}

\begin{abstract}
Creative communities have the potential in promoting a city's cultural and touristic values. In Surabaya, the lack of properly designed spaces to accommodate their unique activities and promote them to the society have become key obstacles observed. Meanwhile, the profit-driven tendency of interior design practice today has led to the decrease in community and social awareness in design education. This research aims to implement participatory methods in the design of community spaces as studio projects to encourage students and lecturers to gain more social awareness of surrounding communities and utilize their expertise to contribute to the society. Through ethnographic methods of observation, students and lecturers participated in a creative community's activities in order to grasp their aspirations empathetically. The community was also invited to participate in the design process of defining problems, setting design goals, ideating concepts and testing design prototypes. Findings reveal that through participatory design, the designs of community spaces yielded can accommodate creative activities in a novel way and assist in promoting their potentials to the society, contributing to the vision of Surabaya as a creative city. Students and lecturers also gain a reflexive introspection of their significant role in the society as agents of social change.
\end{abstract}

Keywords: participatory design, human centered design; Surabaya; community space

\section{Introduction}

Surabaya is the second largest city in Indonesia, historically known as the "City of Heroes" since many famous battles and martyrs died in this city during the nation's fight for independence. Consequently, Surabaya is wellknown for the brave, strong, blunt, highly sociable and straight-forward character of the people, popularly called "arek Suroboyo" in local Javanese slang (Sriyanto and Fauzie, 2017). Such bold and dominating characters are evident in the development of creative communities in Surabaya today. These increasingly active groups of people share interests and passion in various forms of arts, related to local history as well as traditional and contemporary Surabaya culture that are truly unique and have the potential to motivate the general society to become more creative and productive in life. Hence, they are agents of collective creativity and catalysts for the future development of the city. As stated by the head of The Regional Representative Council of Surabaya, communities have the potential to promote Surabaya's local culture and touristic value (Wijayanto, 2017). However, despite the presence of such valuable communities in Surabaya, they lack properly designed spaces that can truly accommodate the communities' various activities. Conventional rented spaces, living rooms of private residential spaces or garages are often used for their activities, with unappealing storage spaces for their art works or collections. They also lack the means that can help in promoting their community's potentials to the public in terms of space and place, causing them to rely heavily on social media.

While these social issues are relevant and could be addressed by architectural and interior designers, the profitdriven tendency of design practice today has led to the decrease in community and social awareness in design education (Kroeker and Singh, 2007). Most of interior design projects, whether in education or professional practice, are commercially-bounded, with forces generated by elite brands, marketing trends or popular styles rather than touching on the social aspects of design. On the basis of this background, this research aims to 
implement participatory methods in the design of community spaces as studio projects to encourage both students and lecturers, as present and future designers, to gain more social awareness of surrounding communities and utilize their expertise to contribute to the society. Through ethnographic methods of observation, students and lecturers participated in a creative community's activities in order to grasp their needs and aspirations empathetically. The community was also invited to participate and involve themselves in the following design process of defining problems, setting design goals, ideating concepts and producing prototypes and performing usability tests. Through this research, it is hoped that the idea and method of implementing mutual designer-community participatory methods in design education as performed in this research may serve as a learning model in improving future interior design learning curriculum that is aimed at building social responsibility and community awareness instead of competing against profit-driven trends in the society.

\section{The Proposed Participatory Learning and Design Process Model}

The learning and design method proposed and used in this research was developed from the approach of participatory design, a human-centered design approach that attempts to involve end-users, experts, community or other individuals in the design process to ensure its usability (Bijl-Brouwer and Dorst, 2017). However, the aim of this method was not only incorporated for such means but also to encourage social interactions in the design process that would in turn ignite the designers' awareness of their community and sense of social responsibility. The employment of participatory learning also facilitates collaborative learning processes and a sense of connectedness between students themselves and with their lecturers, boarding the same boat of educational adventure, fostering a positive academic community (Summers, 2010). At the initial stage, a group of ten students, supervised by one lecturer, were introduced to an existing creative community that would be the object of their studio design project. The design and learning process they must undergo followed the design thinking process adapted from Stanford School of Design (Carroll et. al, 2010), which must be conducted through six stages (figure 1). Based on human-centered design studies, the authors as studio instructors incorporated mutual participatory methods in all the stages of the design and learning process.

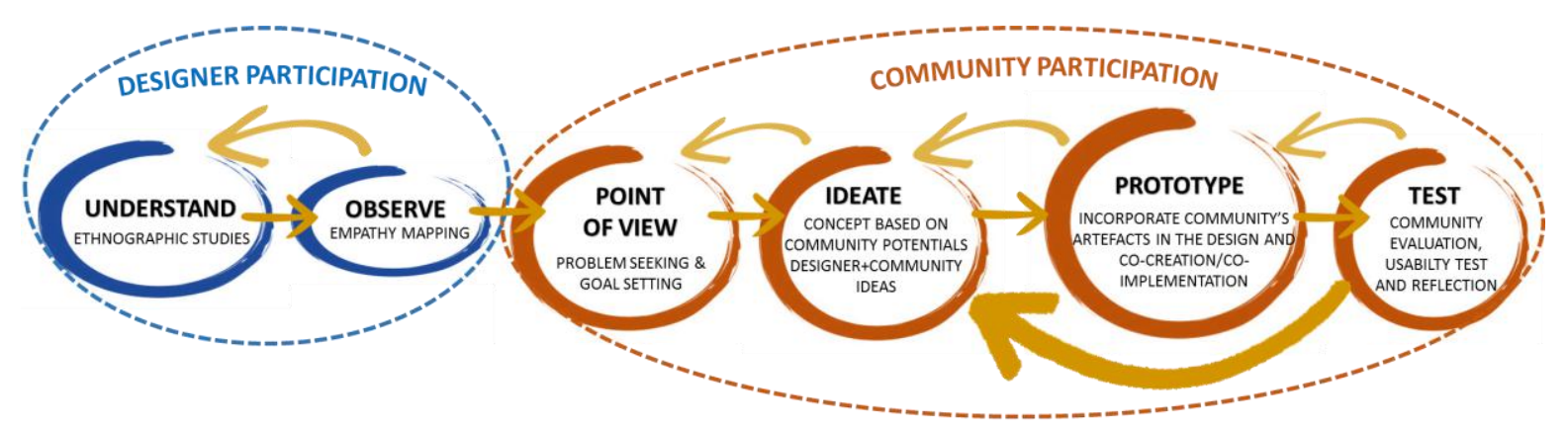

Figure 1: Mutual participatory learning and design process of creative community spaces to encourage collective creativity, social interaction, awareness and responsibility (adapted from Caroll et. al, 2010)

The design process started with the Understand stage, in which students and mentors participated in the creative community's activities using the ethnographic approach, an approach in which the designers involve themselves in the daily lives and activities of a certain community at a their natural setting and for a significant duration of time, in order to gain a deep understanding of the subjects of their research (Balsiger and Lambelet, 2014). The second stage was the Observe stage, in which the designers began to observe their subjects and empathized with both their passions and problems (their gains and pains) through empathy mapping (Ferreira et. al, 2015). The empathy maps helped in determining positive values (gains) of community that ought to be sustained and promoted through the design interventions, while also identifying the problems (pains) that needed to be solved in terms of spatial design. From the Point of View stage, the designers involved the community to participate throughout the design process until its implementation. Both designers and community members determined design needs and set design goals together through affinity diagrams, goal maps and open discussions. Entering 
the Ideation stage, the designers involved the community's ideas to formulate concepts that were based on the community's potentials or values, rather than following popular design concepts or trends in the market. Similarly, in the prototype stage, the designers incorporated all these potentials in terms of skill, art works and atmosphere in the design their spatial elements. There were two types of prototypes that must be produced. First is a conceptual scaled prototype of a $300-500 \mathrm{~m}^{2}$ of interior space based on a real site that was deemed suitable as the community's basecamp. The scaled prototypes were in the form of presentation drawings and a 1:50 scaled mock-up. These prototypes would serve as a useful tool for future basecamp set-ups and design proposals that collaborate with the regional government. The second prototype was the styling or setting of space or spot located in the community's existing basecamp. This prototype should have a direct usability that could assist in accommodating or promoting the community's current activities. The community was encouraged to assist in the design through co-creation and co-implementation to give them a sense of contribution and ownership in the design (Prahalad and Ramaswamy, 2004). In the Test stage, the community was invited to evaluate the first conceptual prototypes produced by various methods such as dot voting and both verbal and written feedbacks. Designers then returned to the ideation and prototype stage again until a final community approved design was yielded. Meanwhile, a summative user test was conducted on the second prototype to ensure its usability to community (Rubin and Chisnell, 2008). Through this active mutual interaction and participatory process, the studio instructors' goal was to increase both the students' and the lecturers' social skills, ignite their social awareness and responsibility according to their interior design expertise.

\section{Results and Discussion}

The community that has been taken as the case study in this paper is a historical military reenactment community who calls themselves "De Mardijkers," referring to a community in colonial Indonesian cities during the Portuguese-Dutch rule that were made up of the descendants of freed slaves (Choudhury, 2014). Their main activities included performing military reenactments in public spaces, collecting both original and replicas of military equipment such as uniforms, weapons, personal belongings and documents. From the Understand to the Observe stage of design, the students and lecturers participated in the community's activities within a period of five weeks. Many activities were performed together ranging from direct participation in military reenactments, wearing military attire, using military belongings and attributes, conversing and making friends with the national history-adorned community (Figure 2).

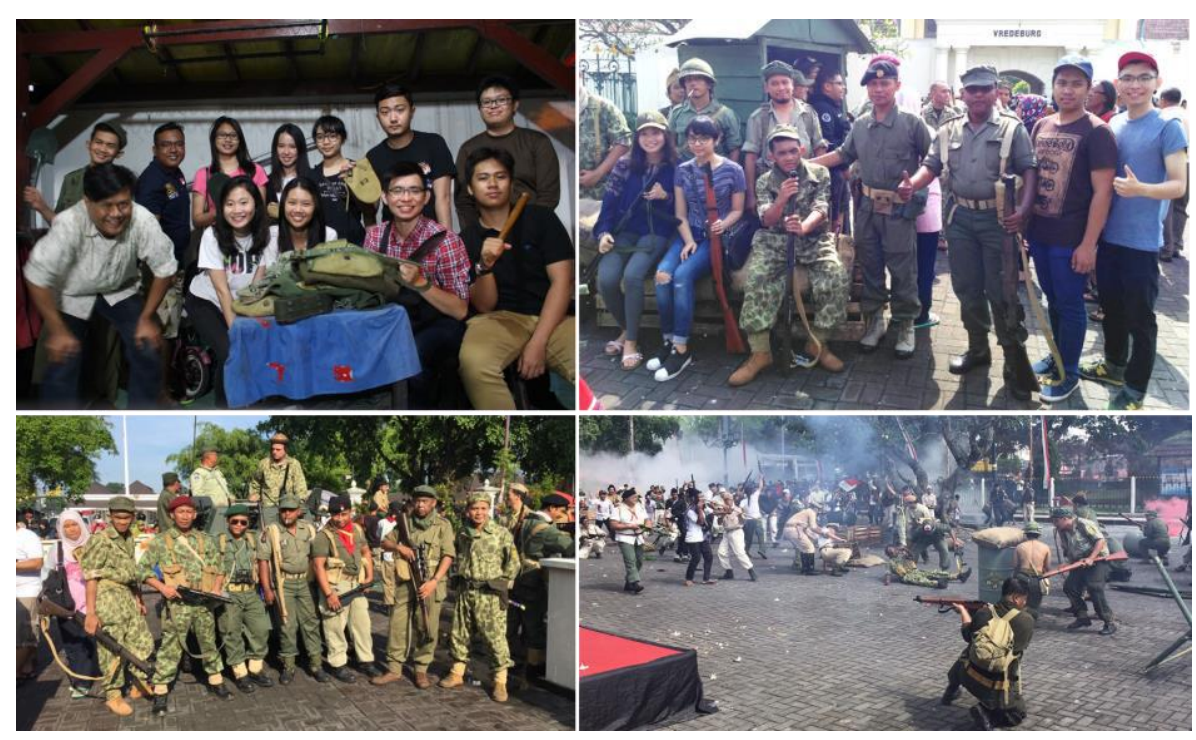

Figure 2: Designers build relations with the community by observing and participating in their gatherings and military reenactment activities using the ethnographic approaches

Through their direct involvement in the community, the designers shared their valuable aspirations, passions and hobbies in an in-depth personal experience that could never have been grasped wholly in the conventional 
project-brief model of learning performed prior to this research project, in which students often remain unconnected from their target clients. The De Mardijker community's aspiration was to preserve the memories of past national heroes and important military events that led to the Indonesian independence. The community members are extremely bold, blunt and creative people, who are passionate about preserving local identity and culture. Their specific passion on national history and pride are truly instrumental in promoting the touristic and cultural values of Surabaya, the creative city of national heroes.

In the Observe to the Point of View stage, the process of empathy mapping was a significant part of the process in determining both the community's potentials that ought be promoted or encouraged, and their needs that ought to be accommodated through their design interventions (Figure 3). The maps permitted the transformation of abstract qualitative data acquired from the ethnographic studies into more concrete and, in some cases, quantitative ones, a process needed before the programming of facilities in interior design. In previous projectbrief model of learning, designers often proceed to the stage of programming before concretely understanding the problems (pains) of the user. Through this process, it was discovered that the community's problems were the lack of means to demonstrate their knowledge on historical events and military memories that could enrich local history and heritage. Their collections were mainly kept in personal spaces that were poorly displayed and categorized despite their potentials in educating the society.

The process of setting up goals with the community through affinity diagrams and open discussions also permitted collective ideas of problem solving from the community rather than solely relying on the students and lecturers as the sole experts, as often the case in previous models of interior design learning. For example, in the case of this community, the main problem to be solved was how design interventions could help sort out their historical artifacts, from military documents to equipment such the communication and appreciation of national history could be addressed in a structured way. The designers and community decided to design a community centre, with educational facilities that could assist in accommodating the community's reenactment activities. Their designs also needed to provide visitors with historical knowledge, evoking emotions through spatial experiences in order to revive their civic and national pride, in memory of the battles and hardships endured by past national heroes, the incidents Surabaya city is known for till today.
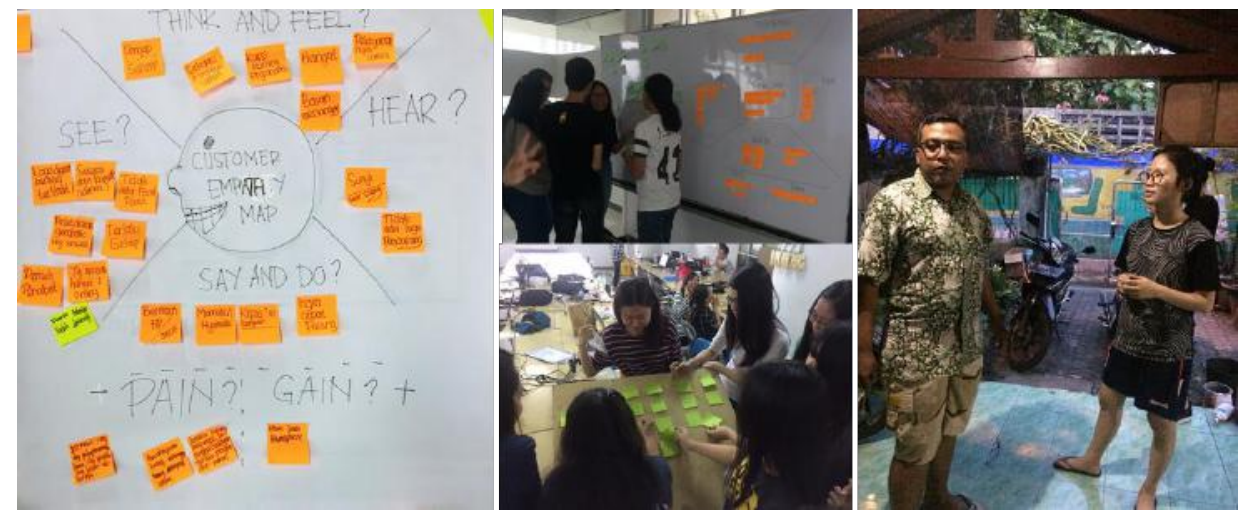

Figure 3: Designers determine community needs and set goals together with the community through empathy maps, affinity diagrams and open discussions

The community's participation in goal setting provided novel insights in the following stage of Ideation. From the problems defined through participatory methods in the Point of View stage, students and lectures realized that innovative design concepts are those that must be based on the community's values and potentials, rather than follow popular design trends in the market. This provided a pathway to innovative designs in which the designers created their own styles based on the usesr rather than follow market-driven forces drawn from popular interior design catalogs and magazines. In the case of this project, the designers formulated a design concept themed as "War in Living Memory," for a conceptual proposal of the De Mardijkers community center. This concept attempted not only to communicate historical facts that led to the nation's independence but also to 
evoke the emotions that still sustains in the lives of people today As a result, the conceptual sketches of interior spaces produced displayed military attributes that were fused with interior elements such as walls, floors and ceilings, creating a new style of artwork in interior design (figure 4). Many interior elements were created to evoke the memories of past battles, the hardships and loneliness, that led to the nation's independence such as interior furnishing with patterns from military clothing, unfinished exposed concrete walls that resembled gloomy military camps, foldable fabric furniture in past military offices, rustic surfaces of colonial styled columns and temporary wooden stages that soldiers used to entertain themselves during the war.

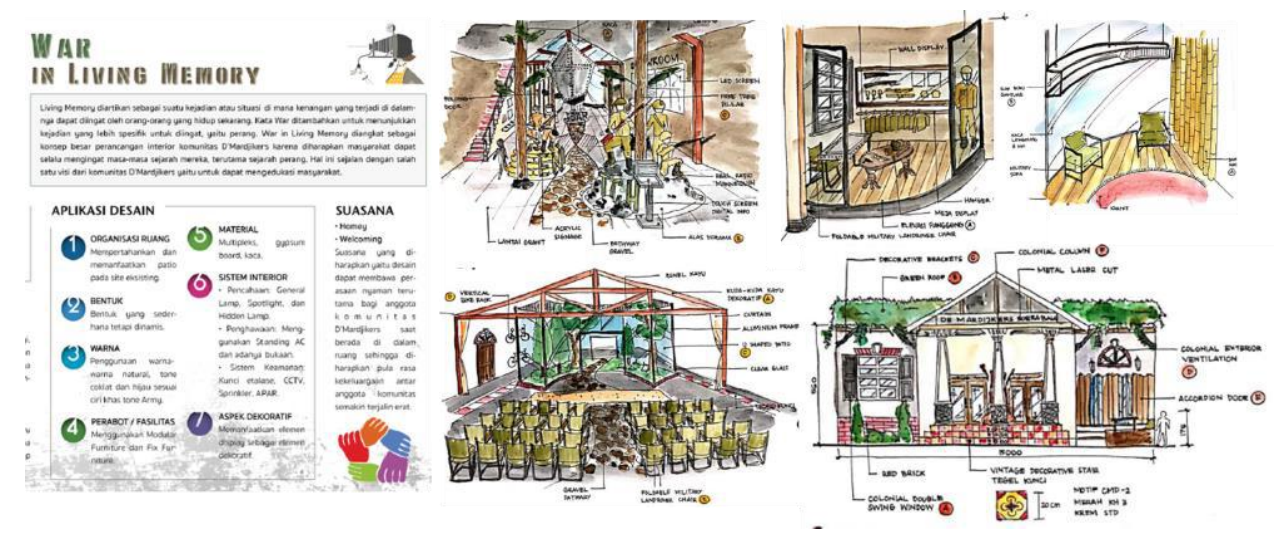

Figure 4: Designers ideate concepts that are based on community's values, passion and potentials and produce conceptual drawings that reflect the memories and emotions of war that led to the nation's independence (diagram by Angela Lisa, conceptual sketches by Anette Firmawan)

The conceptual sketches were further redeveloped into specific spatial programs through realistic interior renderings. From the concept based on community potentials and values, many types of innovative spaces were produced that could be used to educate visitors regarding the historical values, aspired by the community. There were multifunction spaces that could be used for theatrical reenactments for the community and a range of education facilities such as galleries, showcases and replicas of military camps that could help in promoting the historical, cultural and touristic values of Surabaya (figure 5). The galleries were also designed in such a way that they formed a route from entry to exit based on chronological historical events and battles that could evoke the emotions and memories of the past through the reflexive journey inside the building. This conceptual design of a community center could serve as a useful document for future set ups and collaborations with the regional government of Surabaya. 


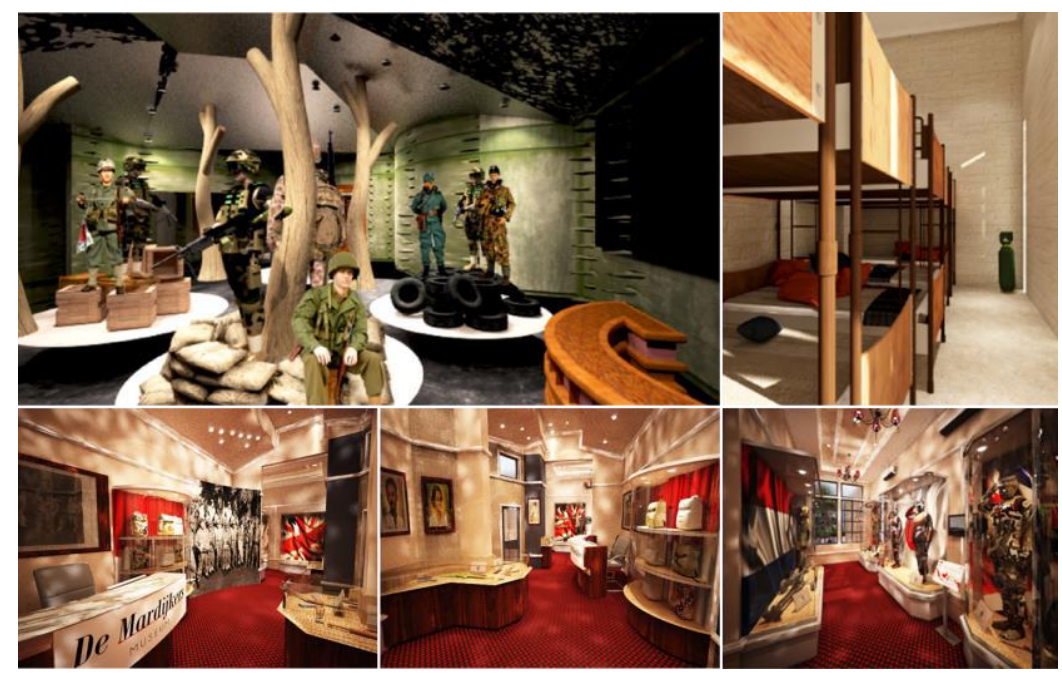

Figure 5: Conceptual interior design of a De Mardijkers community center displaying education facilities such as galleries, showcases and replicas of military camps that could help in promoting the historical, cultural and touristic values of Surabaya (Design by Anette Firmawan and Rudy Putra)

The designs were then displayed on posters and presented to design peers, lecturers and community members (figure 6). This participatory evaluation proved to be truly useful for acquiring feedbacks in order to refine the designs such that they could be truly useful to the community as well as the general public who wish to learn about valuable national history.

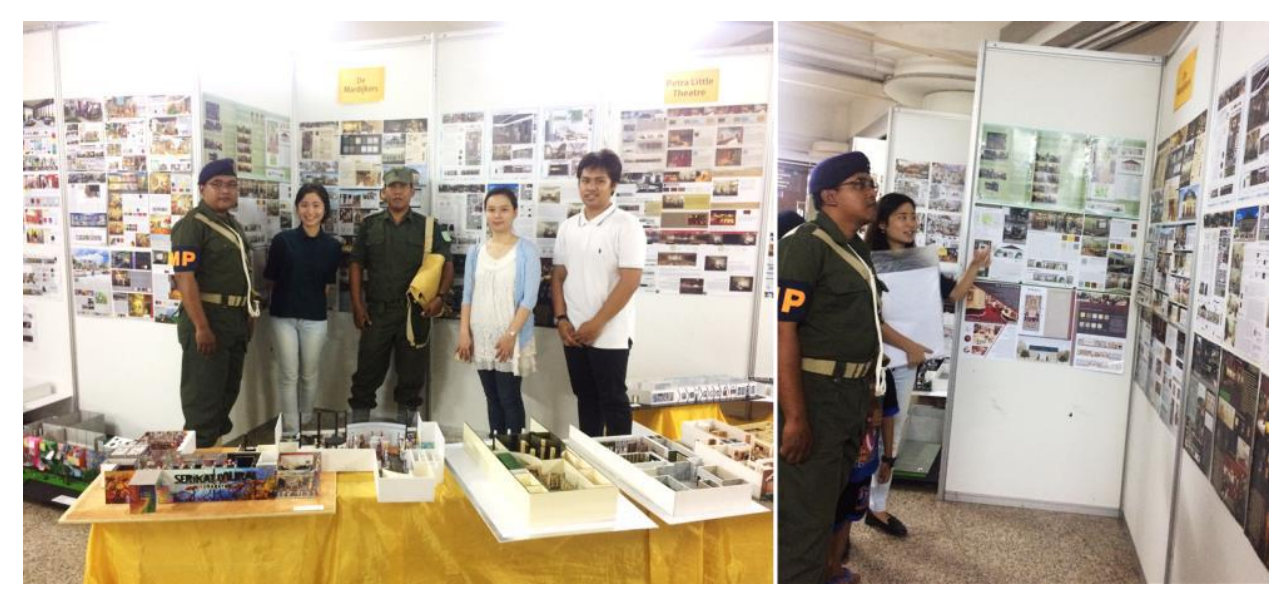

Figure 6: Participatory evaluation of conceptual design prototypes of De Mardijkers Surabaya community center by peers, lecturers and community in order to ensure their usability to the community and the society.

Following the production of the first prototype, the project was then followed by the implementation of a second prototype: the interior styling and setting of the community's present basecamp. The community desired a corner to display a part of their collections of military tools and replicas such that they could serve a background for promotion to visitors of the basecamp as well as in social media. The students and lecturers decided to use recycled materials for displaying the items such as bottle wooden containers as used in the past and pallet wood. These materials were economic, yet artistic at the same time, and they support the atmosphere and image of military camps. The community was not only invited to provide feedbacks but also to collaboratively set up the corner together. This process proved to be a truly a collaborative process of team work between the designers and the community and informal social interactions were further developed through the process. 

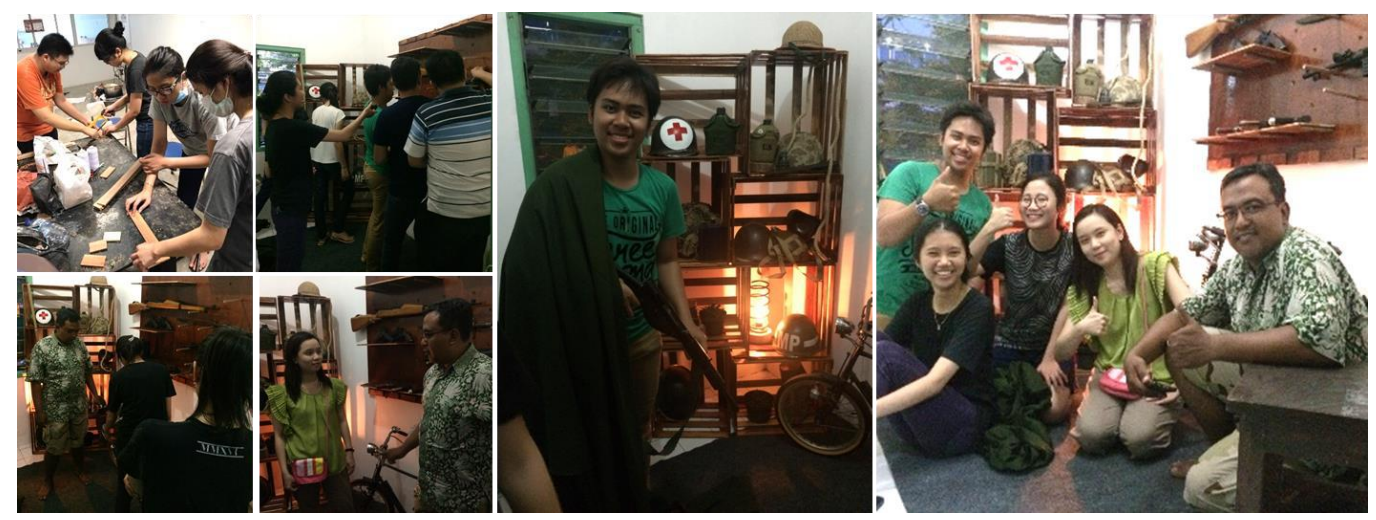

Figure 7: Collaborative set-up and co-implementation process of interior styling followed by summative usability test in the community's current base camp, producing a display corner for a part of the community's personal collections

The collaborative design implementation process resulted in an attractive display corner, despite the lack of space in the community basecamp (figure 8). The display furniture from recycled wood with simple hooks for guns and racks for other military equipment, accompanied with an old bicycle used in past battles, a colonial chair and a manikin dressed in a national army suit, produced an artistic, rustic atmosphere of the olden days, enhancing the image of the community and their aspirations in reviving the heroic memories of the past. Results of summative usability test reveal that this co-created corner has become a useful and creative space that has been instrumental in promoting the community to the general public. The co-designed space has been used as background for photographs in the community's social media and functioned as a mini museum in which visitors can also come and appreciate their collections.

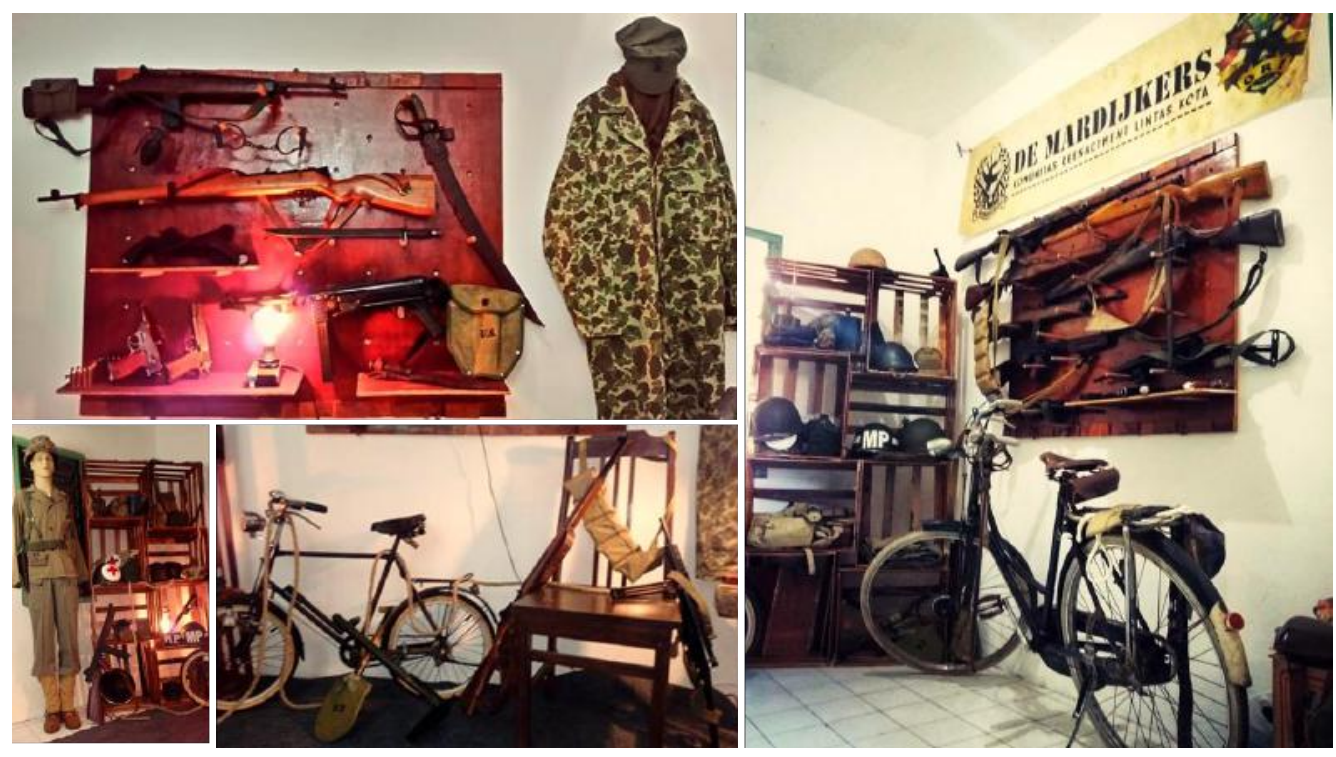

Figure 8: Participatory interior design and styling of the community's display corner, functioning as an identity area in the community's base camp.

From the reflection essays of students and lecturers, they have revealed how the intense interaction with the community has helped them in realizing how important they could be to the society as interior designers. They also revealed their difficulties in trying to understand the unique people and adjusting to their straight-forward and blunt characters. They had to push aside their prejudices and grasp the positive values aspired by the community: their wishes in reviving the memories of national heroes and heroic events that led to the nation's independence. Hence, the participatory method of learning have proved to be successful in providing a 
introspective impact on the part of the designers, on how to become humble citizens in order to understand their surrounding communities, contribute their skills for the welfare of others and take part in promoting the region and nation they live in. On the other hand, reflection essays from the community also revealed their gratitude for the assistance they have received from the students and lecturers. Their involvement in the design process made them feel respected by the students and lecturers. This would in turn elevate the profession of interior designers in the eyes of communities and diminish the prejudice that interior designers are often marketable only to the upper class society.

\section{Conclusion}

Participatory design provides experiential knowledge, yielding many benefits throughout the whole design process (Kanga et. al, 2014). The participation of designers in the initial stage of understand and observing the community helped them to build the same passion in reviving the historical and cultural value of Surabaya and taught them how to understand and respect their surrounding community. Meanwhile, the participation of the community in the following design process, from setting up goals together, ideating prototypes and collaborating with designers in the implementation of the design ensured the usability of the design to the community and the society. Most importantly, the mutual participation in the whole design process triggered social interactions, a sense of connectedness and experiential learning between the designers (students and lecturers) and the community, hence strengthening the community as citizens and elevating their perception of each other as agents of social change. With participatory design, interior designers in both the academic and professional world can produce innovative designs based on their local community and their own unique potentials rather than compete against repetitive catalogue-based styles and market-driven design trends in the contemporary society.

\section{Acknowledgements}

The authors would like to acknowledge the financial support from the Ministry of Research, Technology and Higher Education, Indonesia, in this research study. We would also like to thank Mr. Krishario Llyodino and De Mardijkers community for their collaboration in this research. Special mention also goes to the design team: Drs. Linggajaya Suryanata, Anette Firmawan, Rudy Putra, Angela Lisa, Vincensius Reynald, Stevanus Felix, Steven Anggreawan, Nindya Ayu, Dinda Tamara and Karin Oscarina for their participation in this research.

\section{References}

Balsiger, P. and Lambelet, A., 2014, Participant Observation. In: Methodological Practices in Social Movement Research, edited by D. D. Porta (Oxford : Oxford University Press), pp 144-172.

Bijl-Brouwer, M.v.d and Dorst, K., 2017, Advancing the strategic impact of human-centred design. Design Studies, 53, 1-23

Carroll, M., Goldman, S., Britos, L., Koh, J., Royalty, A. and Hornstein, M., 2010, Destination, Imagination and the Fires Within: Design Thinking in a Middle School Classroom. International Journal of Art and Design Education, 29(1), 37-53.

Choudhury, M., 2014, The Mardijkers of Batavia: Construction of a colonial identity. Proceedings of the Indian History Congress, 75 ( Platinum Jubilee) , pp. 901-910

Ferreira, B., Silva, W., Alves de Oliveira Junior, E. and Conte, T., 2015, Designing Personas with Empathy Map. SEKE, 152.

Kanga, M., Choob, P., Watters., C. E., 2014, Design for experiencing: participatory design approach with multidisciplinary perspectives, Procedia - Social and Behavioral Sciences, 174, pp. 830 - 833

Kroeker, R. and Singh, V, 2007, Material Culture and Design Education. In Design Studio Pedagogy: Horizons for the Future, edited by A. Salama and N. Wilkinson (Gateshead: The Urban International Press), pp. 255-268.

Prahalad, C. K. and Ramaswamy, V., 2004, Co-creation experiences: The next practice in value creation. Journal of Interactive Marketing, 18(3), 5-14 
Proceeding of the $4^{\text {th }}$ International Conference on Education, Vol. 4, Issue 2, 2018, pp. 25-33

Rubin, J. and Chisnell, D., 2008, Handbook of Usability Testing Second Edition (Indianapolis: Wiley Publishing Inc)

Sriyanto, S and Fauzie, A., 2017, Penggunaan Kata "Jancuk" Sebagai Ekspresi Budaya dalam Perilaku Komunikasi Arek di Kampung Kota Surabaya. Jurnal Psikologi Teori \&Terapan, 7(2), 88-102

Summers, J. J., Gorin, J. S., Beretvas, S. N., Svinicki, M. D., 2005, Evaluating Collaborative Learning and Community. Journal of Experimental Education, 73(3), 165-188

Wijayanto, 2017, Komunitas Berpotensi Promosikan Surabaya Usul DPRD Surabaya untuk Datangkan Wisatawan. Radar Surabaya, 19 December 